\title{
Firm Heterogeneity, Credit \\ Constraints, and Endogenous Growth
}

\author{
Jürgen Antony ${ }^{\mathrm{a}}$, Torben Klarl ${ }^{\mathrm{b}}$, and Alfred Maußner ${ }^{\mathrm{c}}$
}

February 2011

\begin{abstract}
This paper is in general concerned with the role of firm heterogeneity for economic growth. We focus on heterogeneous productivity in innovation and credit constraints of firms within a semi-endogenous growth model reflecting recent empirical findings on firm heterogeneity. Our model allows for an explicit solution for transitional growth and balanced growth path level of innovations or ideas. The model predicts an optimal degree of heterogeneity in the presence of an endogenous firm distribution. This enables us to draw inference about the impact of key policy parameters of the model on these quantities and to draw conclusions about firm and capital market related policies.

Keywords: Firm heterogeneity, credit constraints, innovation, economic growth
\end{abstract}

${ }^{a}$ CPB Netherlands Bureau for Economic Policy Analysis, Van Stolkweg 14, NL-2585 JR The Hague, The Netherlands, e-mail: j.antony@cpb.nl, Tel.: +31(0)70-3383-451, Fax: $+31(0) 70-3383-350$.

${ }^{b}$ University of Augsburg, Department of Economics, Universitätsstraße 16, D-86159 Augsburg, e-mail: torben.alexander.klarl@wiwi.uni-augsburg.de, Tel.: +49(0)821-598-4177, Fax: $+49(0) 821-598-4229$.

${ }^{c}$ University of Augsburg, Department of Economics, Universitätsstraße 16, D-86159 Augsburg, e-mail: alfred.maussner@wiwi.uni-augsburg.de, Tel.: +49(0)821-598-4188, Fax: $+49(0) 821-598-4231$. 


\section{Introduction}

In the recent past new data sets have allowed researchers to detect systematic relations between the characteristics of business firms and their participation in foreign trade and investment. This has spurred an increasing number of theoretical contributions that consider the influence of firm heterogeneity on the pattern of foreign trade and international economic integration. More recently firm heterogeneity has been introduced in development studies (e.g. Bond et al. 2008 or Gorodnichenko and Schnitzer 2010) and labor market economics (e.g. Helpman et al. 2008 or Yeaple 2005). Less attention has been paid to possible links between firm heterogeneity and other key economic variables, as, for instance, aggregate productivity or growth.

The focus of this paper is the link between firm heterogeneity, research and development $(\mathrm{R} \& \mathrm{D})$ and innovation in the presence of credit constraints. The empirical evidence reviewed below reveals that a) smaller firms are relatively more innovative than larger ones but b) face more obstacles in accessing the necessary financial leverage.

The contribution of the present paper is twofold. First, we develop a semiendogenous growth model that takes account of the influence of firm heterogeneity in R\&D productivity and credit constraints. Firm heterogeneity is endogenous. To the best of our knowledge this is novel in the literature. ${ }^{1}$ Our model yields an explicit expression for the optimal degree of firm heterogeneity regarding growth and the long-run level of innovations. ${ }^{2}$

Second, by exploiting the comparative static properties of our model with respect to the parameters reflecting heterogeneity in credit constraints and $R \& D$ productivity we shed light on the effects of policy interventions on inno-

\footnotetext{
${ }^{1}$ Peretto $(1998,1999 \mathrm{a}, \mathrm{b})$ is concerned with firm size but only for homogenous firms. Luttmer (2007) and Baldwin and Robert-Nicoud (2008) analyze the relation between heterogeneity in firm level productivity and aggregate productivity

${ }^{2}$ The study that comes closest to what we have in mind when considering the link between firm heterogeneity and growth is Klette and Kortum (2004). However, they do not take account of heterogeneity in innovation behavior of firms nor is firm heterogeneity endogenous.
} 
vation and growth.

The paper is structured as follows. Section 2 provides an overview of the available empirical evidence on firm heterogeneity, growth and innovation as well as firms' access to finance. It motivates our theoretical model developed in Section 3. Results are discussed in Section 4 where we also derive implications for evaluating the recent EU policy initiatives targeted at small and medium sized enterprises (SMEs). Section 5 concludes.

\section{Empirical Findings}

The importance of firm heterogeneity for an economy is generally judged as very high. The most easiest way to distinguish firms is by size. The OECD (2009) for example points to the role of the SME sector in an economy. This is of course due to their dominance in numbers as compared to large scale enterprises. The German federal bureau for statistics (Statistisches Bundesamt) recently released interesting figures for the German economy in $2005 .^{3}$ It reveals that $99 \%$ of all enterprises belong to the SME sector, they are responsible for $60 \%$ of total employment, $35 \%$ of total turnover, $40 \%$ of all gross investments in structures and $46 \%$ of total gross value added. Therefore, it is unsurprising that the SME sector plays so prominent a role in the economic policy debate. ${ }^{4}$ In other industrialized countries the SME sector is on average even more important. In 2003 the world bank released a data base that provides mean values for the time period 1990 to $1999 .^{5}$ Extracting the data for the 30 OECD member countries, which build a relevant comparison group

\footnotetext{
${ }^{3}$ See Klees and Veldhues (2008). This study considers the role of small and medium sized enterprises with up to 250 employees and turnover up to $50 \mathrm{~m} €$ per year or a balance sheet of up to $43 \mathrm{~m} €$ in manufacturing, retail trade, hotel and restaurant industries, transportation, telecommunication and partly the service sector so that about $80 \%$ of all German enterprises are covered.

${ }^{4}$ See Dannreuther (2007) for the European Union SME policy in general and Jousten (2007) for the taxation of SMEs in particular.

${ }^{5}$ See Ayyagari et al. (2007)
} 
for the German economy, reveals that the OECD mean share of SMEs in total employment and value added is $66 \%$ and $49 \%$, respectively. The figures for Germany during that period of time are $60 \%$ and $43 \%$.

Although these are impressive numbers that suggest an important role for the SME sector, there are other numbers which might be used to stress the role of large enterprises, particularly for R\&D investments. Already Acs and Audretsch (1987) reported that large enterprises are responsible for the major part of total R\&D investments. Czarnitzki and Hottenrott (2011) analyze firm level data for Germany and find that the R\&D investment level is monotonically increasing with firm size for the German business sector from 1992 to 2002. Similar results can be found for the Netherland's case. As mentioned by Verspagen (1999), only five multinational Dutch firms were responsible for $64 \%$ of total R\&D investments in 1984, excluding R\&D expenditures abroad. Although this large share collapses to $45 \%$ in 1995 due to cutbacks in R\&D at Philips, this impressively underpins the important role of large enterprises in the case of total R\&D investments. Besides that, larger enterprises may benefit from higher qualified staff compared to enterprises belonging to the SME sector as outlined by Idson and Oi (1999).

There is more than size that distinguishes firms although size seems to play an important role in the literature. In the next two subsections, we try to summarize the findings in the empirical literature on, first, firm heterogeneity, growth and innovation, and second, on heterogeneity and access to finance. Finally, we try to draw conclusions for the theoretical model in Section (3).

\subsection{Heterogeneity, Growth and Innovation}

There are several findings in the literature on the relationship between firm size, growth and innovation. Pagano and Schivardi (2003) analyze the impact of the firm size distribution on the growth of labor productivity. In their sectoral study for European countries they find a positive relationship between the concentration of a sector on fewer and larger firms on the one side and higher 
labor productivity growth on the other side. Carree and Thurik (1998) come to an opposite result. In their study, they investigate the consequences of the transformation process in Europe's manufacturing industries, particularly in the late 1980s and early 1990s, from large firms toward small firms. Based on an industry panel covering 14 manufacturing industries in 13 European countries, they find on average that the employment share of relative large firms has a negative impact on output growth. Audretsch and Thurik (2001), in a more recent contribution, underpin this result: In their panel study for European countries they find that a concentration towards smaller firms positively affects growth.

The emerging picture gains contour from the results of panel data studies. Using the NBER patent citation data base, Plehn-Dujowich (2007) finds that smaller firms produce up to 4 time more patents per U.S. Dolar spend on R\&D than large companies. In addition, patents of small firms are significantly more frequently cited than patents of large companies, indicating a higher innovative content. ${ }^{6}$ Lotti and Schivardi (2005) study the patenting behavior of countries, sectors and firms. They match data of the European Patent Office with the firm level data base AMADEUS (Bureau van Dijk) and find that while the probability of patenting rises with firm size, the patenting intensity, i.e. granted patents relative to employment, falls with employment. ${ }^{7}$

Bertschek and Entorf (1996) use survey data for Belgium, France and Germany on the percentage of sales due to products reported as innovative by the firm. Their results are mixed with U- and hump-shaped as well as monotonic relationships between employment and their measure of innovation. ${ }^{8}$ For the U.S., Bound et al. (1984) and Acs and Audretsch (1990) find U-shaped

\footnotetext{
${ }^{6}$ See, e.g., Hall, Jaffe, and Trajtenberg (2005) for evidence on the usefulness of citations as a proxy for innovation.

${ }^{7}$ Earlier evidence in this direction can be found in Cohen and Klepper (1996), Bound et al. (1984), Acs and Audretsch (1988, 1991), Pavitt et al. (1987).

${ }^{8}$ Entorf (1988) already found a U-shaped relationship for Germany in a comparable study and Cremer and Sirbu (1978) provide similar results for France.
} 
relationships when focusing on similar innovation measures. However, their results provide no insights on the relationship between employment and innovations per employee or any other relative innovation measure as discussed in the preceding paragraph.

Firm heterogeneity has, of course, many dimensions. Besides size, age also matters. Audretsch and Keilbach (2004) use regional data for 8 OECD economies and find that firm entry and exit positively affects regional output growth. Depending on the region, they conclude that up to $40 \%$ of growth is associated with firm turn over. With firm entry and exit they associate entrepreneurship and young innovative firms since entry and exit rates are usually positively correlated. In this context it might be also useful to take a look at the development of entrepreneurship across countries. A usual measure for entrepreneurship is the fraction of the population aged between 18 and 64 active in running a business. The EIM Business \& Policy Research ${ }^{9}$ provides in its Entrepreneurs international (Compendia) data set time series on this measure for 23 OECD countries for 1972 to $2007^{10}$. This entrepreneurial measure declined during this period in 16 of these countries. The unweighted average decline amounts to 3.7 percentage points while the average value 1972 was $17.1 \%$. Since entrepreneurship is closely related to SME activity, ${ }^{11}$ these figures document a clear movement away from a SME to a large enterprise economy.

\subsection{Heterogeneity and Finance}

Firms are also heterogenous with respect to finance. Taking size as the dimension of heterogeneity, Grunert et al. (2002) find the interest rate mark-up for SMEs to be in the range of 1 to 2.5 percentage points p. a. as compared

\footnotetext{
${ }^{9} \mathrm{http}: / /$ data.ondernemerschap.nl

${ }^{10}$ The 23 countries are Australia, Austria, Belgium, Canada, Denmark, Finland, France, Germany, Greece, Iceland, Ireland, Italy, Japan, Luxembourg, New Zealand, Norway, Portugal, Spain, Sweden, Switzerland, The Netherlands, U.K. and U.S.

${ }^{11}$ According to Audretsch (2007) today's entrepreneurship yields tomorrow's SMEs.
} 
to large enterprises. The authors argue that increased capital requirements for banks induced by the Basel II accord are the underlying reason. Further empirical evidence for increasing capital requirements and, hence, increasing refinancing costs can be found in, e.g., Saurina and Trucharte (2004), Altman and Sabato (2005), Jacobson et al. (2005) and Berger (2006).

Going beyond the Basel accord, there is ample evidence in the literature on heterogeneous credit constraints. Bernanke et al. (1996) review the literature on credit constraints in order to support their theory of the financial accelerator. According to their references smaller lenders must provide more collateral than larger and well established ones. Aghion et al. (2007) find from firm level data for 16 industrialized and developing countries that more favorable financial conditions lead to more firm entries and post-entry firm growth. This result is quantitatively most important in sectors which are most reliant on external finance. Lelarge et al. (2010) examine the impact of a public loan guarantee scheme for small firms in France. They find this programme to increase firm's ability in obtaining external finance significantly, pointing to the relevance of constraints for these firms in normal credit markets. Also Wagenvoort $(2003 \mathrm{a}, \mathrm{b})$ finds smaller firms in Europe to be more credit constrained than larger companies. Angelini and Generale (2008) come to the same result for the U.S.

Related to this is the notion of perceived credit constraints. This literature builds almost exclusively on business surveys. Musso and Schiavo (2008) provide a good overview of such studies. The evidence herein supports the conclusion that smaller and younger firms at least feel to be more credit constrained than larger and older ones. In their own empirical work using data on French firms, Musso and Schiavo (2008) arrive at the same conclusion as Aghion et al. (2007).

Relevant to our work is not only size heterogeneity but also heterogeneity with respect to other characteristics. Aghion et al. (2004) elaborate on the structure of finance of $R \& D$ conducting firms. Using a firm level data set for 
the U.K., they find that the share of traditional debt finance in the firms' balance sheets is lower the more innovative a firm is. The authors argue that this is due to higher intangibility of innovative activity which puts a limit on traditional bank lending.

Firms can also be distinguished with respect to their age. Gertler (1988), Devereux and Schiantarelli (1990), Cabral and Mata (2003) and Beck et al. (2006) find younger firms to be more credit constraint than mature ones. Mata (1996) finds that the majority of young firms, which are typically small, are established below their desired or optimal firm size, mainly due to financial constraints.

Also the Bank Lending Survey (BLS) conducted quarterly by the Eurosystem in the Euro area sheds some light on how credit constraints apply to different types of firms. The survey has been conducted since 2003 and covers 90 bank groups in all participating countries. Although limited in detail, the reported numbers in the BLS can give insights on the influence of firm size on credit constraints. During the fourth quarter of 2008 (see ECB 2009 p. 17), i.e. right after the bankruptcy of Lehman Brothers Holdings Inc., the credit standards applicable for approval of credits or credit lines tightened considerably more for SMEs than for large firms. The percentage point difference of banks reporting tightening standards over banks reporting easing standards due to general economic risks increased for SMEs by 16 and for large firms by 5. For reasons of industry or firm related outlook the numbers where 12 and 2, and for risk of the collateral 12 and 5 . It seems therefore that conditions for SMEs detoriated considerably more due to economic risks. But also increased refinancing costs of the lending banks hit SMEs harder than large firms. The percentage point difference of banks tightening and banks easing standards due to refinancing costs increased for SMEs on average by 8 and for large firms only by 3.7 points.

However, the empirical evidence is not unanimous. Hurst and Lusardi (2004) look at business starts in the U.S. They do not find a clear cut relation 
between household wealth and entrepreneurial activity. This holds both for industries with lower and higher capital requirements. Only in the very upper part of the wealth distribution entrepreneurial activity rises with wealth.

What can we learn from the empirical literature about finance and innovation? In general, heterogeneity in access to financial markets is expected to carry over to innovation activity. Financing constraints are crucial for the $R \& D$ sector, since revenues for an $R \& D$ project usually occur in the future

while costs have to be covered today. Scellato (2007) uses firm level panel data for the Italian manufacturing sector. He finds that the total number of patents granted per year to an establishment is significantly negatively influenced by the degree of financial constraints the firm is faced with. However, he does not report any results on relative measures of innovation. The finding is in line with the argument of Almeida and Campello (2004) who claim hat credit constraints are most important for the R\&D sector of an economy, because investments there are likely to be less tangible compared to other sectors and might not serve as a good collateral for external finance.

\subsection{Implications for the Model}

From this review we conclude that a trade-off exists between the comparative advantage of SMEs in relative measures of innovation, and a comparative disadvantage in accessing financial leverage. As a consequence, there might exist an optimal mix of small, medium and large enterprises as conjectured by Audretsch and Thurik (2001) and Mata (1996). The next section considers this optimal mix in a theoretical growth model with credit constraints.

\section{A Theoretical Model of Firm Heterogeneity and Growth}

We consider a second generation growth model and follow Papageorgiou (2003) who provides an extension of the Jones (1995) production function for ideas, 
innovations or new blueprints. ${ }^{12}$ This function allows for both innovation and imitation or technology adoption. As we study heterogeneous R\&D firms, we believe that both $\mathrm{R} \& \mathrm{D}$ types are potentially important. We do not, however, simply apply this function literally but in the way laid out below.

Consider a R\&D firm born at some date $t_{0}$. At birth the firm inherits the state of the art technology $A_{a}=A_{t_{0}}$. Yet, while the state of the art grows over time, the firm's knowledge parameter $A_{a}$ remains constant so that the gap $a \equiv A_{a} / A_{t} \in[0,1]$ between the initial and the leading edge technology widens. At every instant of time $t$ the firm's flow output of ideas $\dot{Z}_{a, t}$ is given by the function

$$
\dot{Z}_{a, t}=\mu L_{a, t}^{\lambda}\left(\frac{A_{a}}{A_{t}}\right)^{\phi} Z_{t}^{\psi}, \quad \mu>0, \lambda \in(0,1), \psi \in[0,1) .
$$

In this function $L_{a, t}$ is the amount of labor employed and $Z_{t}$ is the aggregate flow of ideas. We assume decreasing returns to labor in $\mathrm{R} \& \mathrm{D}, \lambda \in(0,1)$ and a spillover effect captured by the parameter $\psi \in[0,1)$. The parameter $\phi$ captures a second spillover: it determines whether the distance to the frontier $A_{a} / A_{t}$ hampers or promotes the firm's productivity, $\phi>0$ or $\phi<0$, respectively. To simplify notation we drop the time index $t$ in the following where ever no confusion can arise.

We assume a unit mass of firms. Each firm faces a probability of exiting the market governed by the Poisson rate ${ }^{13}$

$$
x=\sigma_{1} \frac{\dot{Z}}{Z}, \quad \sigma_{1}>0
$$

where $\dot{Z}=\int_{0}^{1} \dot{Z}_{a} d F(a)$ is the aggregate rate of innovation and $F(a)$ the cumulative distribution of firms indexed by $a$. This implies that a high aggregate rate of innovation is associated with a high rate of firm exits. Exit in turn builds the basis for new entries in our model.

\footnotetext{
${ }^{12}$ For a discussion of different types of growth models and ideas production functions as well as their appropriateness see e.g. Jones $(1999,2005)$.

${ }^{13}$ This assumption might be justified as to reflect the empirical positive correlation between firm exit and entry and aggregate productivity growth, see e.g. Audretsch and Keilbach (2004) on such empirical evidence.
} 
As in Aghion and Howitt (1998), Section 3.1 we assume that the rate of growth of the state of the art level of technology is directly proportional to the rate of growth of ideas:

$$
\frac{\dot{A}}{A}=\sigma_{2} \frac{\dot{Z}}{Z}, \quad \sigma_{2}>0 .
$$

We show in Appendix A.1 that (2) and (3) imply the stationary distribution

$$
F(a)= \begin{cases}a^{\sigma} & \text { for } 0<a \leq 1, \quad \sigma=\frac{\sigma_{1}}{\sigma_{2}} \\ 0 & \text { else }\end{cases}
$$

and we will assume that at $t$ the actual distribution has already converged to this function. ${ }^{14}$

Thus, a firm $a$ is born and enters the market with $a=1$. Through aggregate innovations its technology position relative to the frontier worsens over time and eventually converges toward 0 if the firm does not exit. This way of modelling has similarity with the modelling strategy in Schumpeterian growth models in the spirit of Aghion and Howitt (1992), where a firm produces intermediate goods of a certain quality level which is at the quality frontier when the firm enters and below when the firm grows old and further innovations push the frontier ahead. This similarity mirrors itself in the distribution of $a$. The exit and entry rate of the economy clearly shapes the firm distribution. With a high $\sigma_{1}$ we have relatively more firms close to the frontier and relatively less far behind it which nevertheless can profit from the frontier through imitating and technology adoption. The expected value of $a$ is given by $\frac{\sigma}{\sigma+1}$.

Once a firm has discovered a new idea, this idea will produce an income stream with present value $V$ that depends on the economy outside the R\&D sector. To derive our results we need no model of this part of the economy. This model must just imply the same, possibly time dependent $V$ for all $a \in[0,1]{ }^{15}$

\footnotetext{
${ }^{14}$ The above distribution is asymptotical, i.e. it is reached asymptotically from any starting distribution for $a$ independent from the remainder of the model as in Aghion and Howitt (1992).

${ }^{15}$ Readers familiar with the growth literature can easily imagine the kind of technical apparatus that will yield $V$.
} 
Before introducing credit constraints into our model, we briefly consider the case of a perfect capital market. In order to pay the wage bill, the R\&D firm has to borrow that part of $V$ attributable to labor. Paying the part determined by the marginal product of labor to their workers, yields the perfect competition solution with wage rate $w$ equal to

$$
w=\mu L_{a}^{\lambda-1} a^{\phi} Z^{\psi} \lambda V
$$

With an identical wage rate across firms, which we assume due to perfect competition in the labor market, different distances to the frontier are compensated by a corresponding marginal product of labor determined by the level of employment, $L_{a}$.

We introduce credit constraints into our model by following the basic idea of credit monitoring cost as in Townsend (1979) and Gale and Hellwig (1985). Costly monitoring of borrowers is necessary to induce compliance to credit rules. As in the case of perfect credit markets above, i.e. zero monitoring costs, the present value of the idea's income stream serves as the collateral for the credit. With costly monitoring it has, however, not only to cover the employee's wage bill but also the monitoring cost. As e.g. in Bernanke et al. (1999) we assume that monitoring cost are directly proportionalto the total volume of credit. We denote by $1-v_{a}$ the amount of credit that is used up to cover these cost, implying that the $v_{a}$ is effectively available to finance the wage bill of the employees. With this formulation we take account of the possibility that credit constraints might depend on the firm's distance to the frontier, i.e. we take account of heterogeneity in credit market access. ${ }^{16}$ With constrained credit opportunities, the wage rate is given by

$$
w=\mu L_{a}^{\lambda-1} a^{\phi} Z^{\psi} v_{a} \lambda V
$$

\footnotetext{
${ }^{16}$ This type of heterogeneity might also be interpreted in a different way. To put it in a somewhat abstract fashion, we introduce here a heterogeneous friction affecting the effective market value of the firms output. This could also be related to something different than credit market access and might refer to a general market imperfection.
} 
The idea of credit constraints affecting the firm's employment decision via a first order condition as (5) can also be found in Greenwald and Stiglitz (1987) who elaborate on the relation between imperfect information on credit markets and unemployment.

In order to obtain a closed form solution in our model, we have to make an assumption for the yet unknown function $v_{a}$. We chose a power function of the form $v_{a}=\nu a^{\gamma}$. There are two points that need to be discussed about this particular function. First, its economic contend and intiution, and second, the implications of its domain.

We start the discussion with the function's economic implications. Although the function seems at first sight a strong ad hoc assumption, it corresponds well with modelling credit frictions in the literature.This function implies that aggregate monitoring cost are directly proportional to the credit volume at any given point in time. Thus, this reflects the idea of proportionate monitoring cost spread in a heterogeneous manner across firms depending on their relative position to the frontier. Bernanke et al. (1999) introduced credit monitoring cost into a DSGE model to analyze the dynamic implication of the financial accelerator. With homogenous firms they also work with directly proportional monitoring cost in the aggregate level.

The formalization $v_{a}=\nu a^{\gamma}$ states that a new born firm at the frontier with $a=1$ has effectively the fraction $\nu$ of the value of their ideas available to pay wages for its $\mathrm{R} \& \mathrm{D}$ workers. If $\gamma<0(=0,>0)$, the available fraction increases (stays constant, decreases) with the distance to frontier and hence firm age. We believe that $\gamma<0$ is a relevant parameter restriction to reflect e.g. the usual bank behavior. Younger firms usually have more problems when applying for credit than older established ones and are more constrained.

To see that we arrive in the aggregate at the same monitoring cost structure as Bernanke et al. (1999), we first calculate the total volume of credit $K$ which is collateralized by the present value of income streams of new ideas

$$
K=\int_{0}^{1} w L_{a} d F(a)=\lambda V \int_{0}^{1} \dot{Z}_{a} d F(a) .
$$


Second, the part of $K$ covering total monitoring cost is given by

$$
M=\int_{0}^{1}\left(1-v_{a}\right) w L_{a} d F(a)=\lambda V \int_{0}^{1}\left(1-v_{a}\right) \dot{Z}_{a} d F(a) .
$$

The ratio $\frac{M}{K}$, thus, equals

$$
\frac{M}{K}=\frac{\int_{0}^{1}\left(1-v_{a}\right) \dot{Z}_{a} d F(a)}{\int_{0}^{1} \dot{Z}_{a} d F(a)}=1-\frac{\int_{0}^{1} v_{a} \dot{Z}_{a} d F(a)}{\int_{0}^{1} \dot{Z}_{a} d F(a)} .
$$

Solving (5) for the firm's employment $L_{a}$ and inserting this in (6) together with the distribution (4) gives $^{17}$

$$
\frac{M}{K}=1-\nu \frac{\sigma(1-\lambda)+\phi+\lambda \gamma}{\sigma(1-\lambda)+\phi+\gamma}
$$

We will see below that a meaningful solution of the model requires $\sigma(1-$ $\lambda)+\phi+\gamma)>0$ so that for $\nu \in[0,1) M / K \in(0,1]$. In addition, $M / K$ is time invariant and monitoring cost are directly proportional to the total credit volume. This implies that $1-(M / K)$ is available in the economy for wage payments in $\mathrm{R} \& \mathrm{D}$ while the fraction $M / K$ covers monitoring expenses of the financial sector. ${ }^{18}$

The second discussion point is concerned with the function's domain. $v_{a}$ changes for the individual firm as it grows old and $a$ declines. With $\gamma<0$, this implies that younger firms have to start with a credit fraction $1-\nu$ that is used to cover monitoring cost. However, later on $1-\nu a^{\gamma}$ declines and might even become negative is the firm stays long enough in the market. We interpret this the following way. As a young firm enters the market, it has to pay excessive monitoring cost, only at a later stage they can regain these "losses" from the beginning as $1-\nu a^{\gamma}$ decreases. Firms are underborrowing in the beginning and overborrowing later on. However, there is no possibility of overborrowing at the aggregate level. As demonstrated in the paragraph above, $\frac{M}{K} \in(0,1]$

\footnotetext{
${ }^{17}$ See Appendix A.2.

${ }^{18}$ In this formulation of the model, a firm that applies for a credit faces credit conditions where monitoring cost are added to the applied credit volume to yield the total amount of debt. This is a quite common practice in the banking sector.
} 
for $\gamma<0$ and at every instance in time overborrowing by older firms with a low $a$ is compensated by underborrowing of young firms with high $a$. The distribution of monitoring cost across all firms is assumed to be reflected by the chosen function for $v_{a}$.

Given these results it is now easy to determine the aggregate rate of growth for the measure of ideas $Z$. Using the definition $\dot{Z}=\int_{0}^{1} \dot{Z}_{a} d F(a)$, the distribution (4) together with the first order condition (5) and $v_{a}=\nu a^{\gamma}$ yields $^{19}$

$$
g \equiv \frac{\dot{Z}}{Z}=\mu L^{\lambda} Z^{\psi-1}\left(\frac{\sigma(1-\lambda)}{\sigma(1-\lambda)+\phi+\gamma}\right)^{-\lambda}\left(\frac{\sigma(1-\lambda)}{\sigma(1-\lambda)+\phi+\lambda \gamma}\right)
$$

where $L$ is aggregate amount of labor used in the $\mathrm{R} \& \mathrm{D}$ sector, i.e. $L=$ $\int_{0}^{1} L_{a} d F(a)$. Firm heterogeneity is captured by the two constant terms in parentheses. Equation (8) holds along the transition path, when the supply of R\&D workers is changing over time. ${ }^{20}$ It is interesting to note that the reduced form (8) is directly comparable to the production function for ideas in Jones (1995) and the model could be seen as a more detailed micro structure for the macro approach in his paper.

Obviously, for our model to be meaningful, the parameters must satisfy $\sigma(1-\lambda)+\phi+\gamma>0$ so that the growth rate is positive. Given this, we can easily evaluate the growth rate with respect to several key parameters.

It is easy to verify that $g$ has a maximum for $\phi<0 \mathrm{at}^{21}$

$$
\sigma^{*}=-\frac{(\gamma+\phi)(\phi+\lambda \gamma)}{(1-\lambda) \phi}
$$

Remember that $\phi<0$ captures the assumption that being at the frontier is not sufficient to be the most productive firm in producing new ideas or blueprints, since firms that are further away from the frontier benefit from imitating or adopting. The non-degenerate distribution of firms associated with $\sigma^{*}$ reflects different mixtures of advantages and disadvantages. 1) Older firms

\footnotetext{
${ }^{19}$ See Appendix A.3.

${ }^{20}$ We will consider the long run growth rate below.

${ }^{21}$ See Appendix A.4
} 
are valuable both due to their adoption capabilities and their easy access to financial markets, but suffer from decreasing returns to labor. 2) By employing only few researchers, younger firms profit from high labor productivity and are, thus, able to compensate their financial disadvantage and their limited adoption potential.

The main result of an interior solution for $\sigma$ stays intact even without credit frictions, i.e. $\gamma=0$. In this case, $\sigma^{*}$ is smaller and it is optimal to have fewer frontier and more older adopting R\&D firms, since through loosening of credit constraints frontier firms tend to employ more researches and thereby decrease their productivity advantage vis-a-vis older firm. Furthermore, there is a dynamic reasoning for firms close to the frontier. Firms at the frontier today are the firms with an advantage in imitation or adoption tomorrow. This argument is inherent in the way firm heterogeneity emerges in the model.

If, however, frontier firms are, ceteris paribus, more productive than technology adopting firms, $\phi>0$, there is no interior solution to the maximization problem. ${ }^{22}$ Instead, the growth rate of ideas increases with $\sigma$. The optimal firm distribution, thus, is degenerate and all firms are located at the frontier with $a=1$. The advantage of being at the frontier overcomes all other forces that work in the opposite direction, i.e., diminishing returns to labor and tighter credit constraints.

To gain further insights into the properties of our model consider the behavior of the innovation intensity, i.e., the flow of ideas per unit of labor. Dividing the production function for ideas on both sides by $L_{a}$ and using (A.4) from Appendix A.3 to substitute for $L_{a}$ yields

$$
\frac{\dot{Z}_{a}}{L_{a}}=\mu a^{-\gamma}\left(\int_{0}^{1} a^{\frac{\phi+\gamma}{1-\lambda}} d F(a)\right)^{1-\lambda} L^{\lambda-1} Z^{\psi}
$$

Without credit frictions, $\gamma=0$, all firms choose the same innovation intensity. If credit frictions are more severe for young firms close to the technology frontier, $\gamma<0$, these firm compensate their disadvantage by employing few

\footnotetext{
${ }^{22}$ See Appendix A.4.
} 
researches in order to gain from the ensuing high marginal productivity. As firms grow old, their innovation intensity decreases. This result is independent of the sign of $\phi$. Although credit constraints are not necessary in the model to obtain an interior solution for $\sigma^{*}$, they are important to explain the empirical findings of heterogeneous innovation intensities.

Multiplying (10) on both sides by $L_{a}$ using (A.4) from Appendix A.3 implies the reduced form of the production function for ideas:

$$
\dot{Z}_{a}=\mu a^{\frac{\phi+\lambda \gamma}{1-\lambda}}\left(\int_{0}^{1} a^{\frac{\phi+\gamma}{1-\lambda}} d F(a)\right)^{-\lambda} L^{\lambda} Z^{\psi} .
$$

Thus, the firm-age profile of the flow of ideas depends on the sign of $\phi+\lambda \gamma$. If both $\gamma<0$ and $\phi<0$, the flow of ideas increases with firm age, and, thus, displays a firm-age profile opposite to the profile of innovation intensity. If frontier firms are more productive than older ones, $\phi>0$, and credit frictions are less severe, $|\lambda \gamma|<\phi$ this age profile still holds.

Finally, consider the size distribution of firms. In Appendix A.3 we derive the relation between the aggregate amount of $\mathrm{R} \& \mathrm{D}$ labor input $L$ and labor services employed by a specific firm $a$ :

$$
L_{a}=\frac{a^{\frac{\phi+\gamma}{1-\lambda}}}{\int_{0}^{1} a^{\frac{\phi+\gamma}{1-\lambda}} d F(a)} L .
$$

If the parameters guarantee an interior solution for $\sigma^{*}$ in equation (8), i.e, $\phi<0$, young firms at the frontier employ less workers than older firms. This may even hold in the case of $\phi>0$, if credit frictions are sufficiently severe so that $\phi+\gamma<0$.

Table 1 summarizes our findings on innovation, innovation intensity and firm size regarding employment. Columns (1) to (3) assume the case $\gamma<0$ while columns (4) and (5) deal with homogenous credit constraints, i.e. $\gamma=0$. We find the case in column (1) the most appropriate one with respect to the empirical findings reported in Section 2. Here we observe young frontier firms that suffer from credit constraints. Their total employment is low but their innovation intensity is high compared to older and larger firms behind the 
frontier. Case (2) shares these properties, however, in this economy there is no role for older technology adopting firms. It would be beneficial to place all firms at the frontier since (9) is only a valid maximum for $\phi<0$. This is also true for the case considered in column (3). Yet, here the case for frontier firms is even stronger. All of the key variables increase as we move towards the frontier. Finally, columns (4) and (5) consider homogenous credit constraints. $^{23}$ As compared to column (1) frictionless credit markets do not change the firm-age profile of the flow of ideas and of employment. Innovation intensity, however, would be homogenous and would, thus, not correspond to what we observe in reality.

Table 1:

Summary of findings

\begin{tabular}{lccccc}
\hline \hline Variable & $(1)$ & $(2)$ & $(3)$ & $(4)$ & $(5)$ \\
& $\phi<0$ & $\phi>0$, & $\phi>0$, & $\phi<0$, & $\phi>0$, \\
& $\phi+\gamma<0$ & $\phi+\gamma<0$ & $\phi+\gamma>0$ & $\gamma=0$ & $\gamma=0$ \\
\hline$\dot{Z}_{a} / L_{a}$ & + & + & + & 0 & 0 \\
$\dot{Z}_{a}$ & - & - & + & - & + \\
$L_{a}$ & - & - & + & - & + \\
\hline \hline
\end{tabular}

From the growth rate (8) we can also infer the level of ideas $Z^{*}$ on the balanced growth path (BGP). We associate the BGP with constant growth rates of labor and ideas. Differentiating $g$ in equation (8) with respect to time yields:

$$
\frac{\dot{g}}{g}=\lambda \frac{\dot{L}}{L}+(\psi-1) g .
$$

Thus, for $g$ to be constant, the growth rate of ideas and rate of growth of the labor force $n \equiv \dot{L} / L$ must satisfy

$$
g=\frac{\lambda}{1-\psi} n
$$

\footnotetext{
${ }^{23}$ The same results apply for an economy without any credit constraints.
} 
Using this result in (8) gives the steady state level of ideas $Z^{*}$ :

$$
\begin{aligned}
Z^{*} & =\left(\frac{\lambda}{1-\psi} \frac{n}{\mu}\right)^{-\frac{1}{1-\psi}} L^{\frac{\lambda}{1-\psi}}\left(\frac{\sigma(1-\lambda)}{\sigma(1-\lambda)+\phi+\gamma}\right)^{-\frac{\lambda}{1-\psi}} \\
& \times\left(\frac{\sigma(1-\lambda)}{\sigma(1-\lambda)+\phi+\lambda \gamma}\right)^{\frac{1}{1-\psi}}
\end{aligned}
$$

Comparing (13) with (8) demonstrates that heterogeneity plays qualitatively the same role for the level and for the growth rate of ideas. Of course, this is an implication of all second generation growth models, where the level of technology simply reflects the properties of the past growth rates. In so far, our arguments from the preceding paragraphs apply for the long-run, too: The optimal degree of firm heterogeneity is either obtained at $\sigma^{*}$ given by equation (9) or at $a=1$ for all firms.

Note that (12) exactly replicates the BGP result in Jones (1995) and confirms our remark from above that heterogeneity affects growth only on the transition path. In the very long run, however, the dependence on heterogeneity in transition manifests itself in the long run level of ideas $Z^{*} .^{24}$

\section{Discussion and Policy Implications}

We first discuss the model's results and then turn to their implications for economic policy.

\subsection{Discussion of Theoretical Results}

Our model demonstrates that there is an optimal firm size distribution whenever larger and older R\&D firms have an advantage through adoption of technology, i.e. $\phi<0$ in the presence of credit constraints that do not favor smaller firms. If there is no comparative advantage through adoption, the optimal firm distribution would degenerate with only new born firms at the frontier. Optimality is defined as maximizing the growth rate of ideas off the balanced

\footnotetext{
${ }^{24}$ This parallels the conclusion in Jones (1995) that growth is only endogenous on the transition path and only the level of ideas is endogenous in the very long run.
} 
growth path (BGP) and the level of ideas on the BGP. The model could therefore serve as a rational for the conjectures in Mata (1996) and Audretsch and Thurik (2001).

In their empirical analysis, Audretsch and Thurik (2001) already followed these ideas partly. However, they concentrated on growth rates alone not taking account of level BGP effects. In the light of the theoretical results above, we must note that focusing on growth rates is not sufficient. As our model predicts, growth rates are only affected by the distribution of firm size off the BGP. This is especially important, if long time series are considered. In this case we would expect the economy to fluctuate around the BGP and effects on the growth rate might be (partly) hidden away so that estimates could be biased. This bias is likely to indicate the unimportance of firm heterogeneity.

Another point worth mentioning in the light of our results is their relevance in the political debate. We saw that there is an optimal distribution of firms in the sense of an optimal $\sigma^{*}$. This value depends on a number of model parameters as is clear from the result in (9). The partial derivatives of $\sigma^{*}$ $\operatorname{are}^{25}$

$$
\frac{\partial \sigma^{*}}{\partial \gamma}<0, \quad \frac{\partial \sigma^{*}}{\partial \phi}<0, \quad \frac{\partial \sigma^{*}}{\partial \lambda}>0 .
$$

If $\gamma$ increases, i.e. differences in heterogeneous credit constraints decline since $\gamma<0$, the optimal $\sigma^{*}$ declines. This has its reason in credit constraints restricting employment strongest in frontier firms. If constraints are loosened, a firm close to the frontier finds it optimal to employ more workers. Given the exogenous supply of labor, fewer firms close to the frontier can be sustained in the optimum and $\sigma^{*}$ declines. If $\phi$ increases, i.e. if technology adoption far from the frontier becomes less important but innovating at the frontier is more productive, the same logic applies. Firms at the frontier employ more workers and hence relatively less of them can stay in the market in optimum. If $\lambda$ increases, i.e. the elasticity of the flow of new idea with respect to R\&D labor rises, the concavity of the production function with respect to labor declines.

\footnotetext{
${ }^{25}$ See Appendix A.6.
} 
This concavity shapes the comparative advantage of small firms close to the frontier as the steepness of the ideas production function determines the high marginal productivity of their fewer workers. A rise in $\lambda$ takes away part of this advantage leading them to employ even fewer workers and gives room for more firms close to the frontier in the optimum.

Also the growth rate $g$ as well as the BGP level of ideas $Z^{*}$ depend on the model's parameters. It is straightforward to calculate their partial derivatives ${ }^{26}$

$$
\begin{array}{ll}
\frac{\partial g}{\partial \gamma}>0, & \frac{\partial Z^{*}}{\partial \gamma}>0, \\
\frac{\partial g}{\partial \phi} \gtreqless 0, & \frac{\partial Z^{*}}{\partial \phi} \gtreqless 0,
\end{array}
$$

Increasing $\gamma$ is beneficial for growth and the BGP level of ideas $(\gamma<0)$. Removing heterogeneity in credit constraints, and with this the comparative disadvantage of smaller firms close to the frontier with high innovation intensity, increases the overall rate of growth in ideas.

Changing $\phi$, i.e. the parameter which shapes the capability of firms far from the frontier to adopt technology, can influence growth and the BGP level of ideas in a positive or negative manner. The inequality signs above correspond to the cases where $\sigma \lesseqgtr-\frac{(1+\lambda) \gamma+\phi}{1-\lambda}>0$. Increasing the capability of adoption, i.e. decreasing $\phi$, is beneficial if there are relatively more firms which make use of this change, i.e. if $\sigma$ is small. If, however, there are fewer of them, i.e. $\sigma$ is high, increasing adoption capability is not beneficial.

There are important cross relations between $\sigma^{*}$ and $\frac{\dot{Z}}{Z}$ and $Z^{*}$. As just explained, a rise in $\gamma$ increases $\frac{\dot{Z}}{Z}$ and $Z^{*}$ but reduces $\sigma^{*}$. Consider a situation where an economy has a firm distribution deviating from the optimal, e.g. $\sigma>\sigma^{*}$ with more firms closer to the frontier than optimal. Loosening of credit constraints is well increasing the growth rate of new ideas but moves the economy even further away from the optimal firm heterogeneity, $\frac{\partial \sigma^{*}}{\partial \gamma}<0$. Such a policy well increases actual growth but at the same time it also increases the potential gain for growth through moving $\sigma$ closer to $\sigma^{*} .{ }^{27}$ Therefore, although

\footnotetext{
${ }^{26}$ See Appendix A.7.

${ }^{27}$ The new maximum value of $\frac{\dot{Z}}{Z}$ and $Z^{*}$ with the higher $\gamma$ must be larger than with a
} 
growth increases, the inefficiency of the economy due to its firm heterogeneity increases as well. One policy might increase the effect of yet another policy, in this case related to the parameter $\sigma$.

\subsection{Policy Implications}

From these results we can draw important policy conclusions. The first conclusion, which is an immediate result of the existence of an optimal distribution, is that there can be too much of SME supporting policies. Before deciding on general policies directed to SMEs, it should be clear that the corresponding SME sector is too small compared to (9). Although this conclusion is rather simplistic, it is hard to come by empirical evidence on this simple question. Drawing again on the SME database of Ayyagari et al. (2007) shows that the share of SMEs in total employment ranges from a low $56 \%$ in the U.K. to a high of $87 \%$ in Greece. ${ }^{28}$ It seems not straightforward to conclude that e.g. a harmonized EU policy directed to SMEs is a good choice.

To proceed further, we take a look at our theory guided results from above. We discussed the role of the parameters $\gamma, \phi, \lambda$. These parameters can clearly be addressed by policy. $\gamma$ is reflecting the heterogeneity of credit constraints. A form of regulation that can be associated with this parameter is certainly the Basel accords. While their primary aim is to help regulators to improve stability of the financial system (see e.g. BIS 2009), their implications carry over to shape the growth potential of an economy. There is likely to arise a trade-off between innovation and stability. This trade-off is, however, not visible from our model since elements of e.g. uncertainty are totally absent.

$\phi$ determines the innovation capabilities depending on the distance from frontier. Strong patent regulations might increase $\phi$ and firms at the frontier gain in advantage while older firms might have problems in adopting technology

lower $\gamma$ since $\frac{\dot{Z}}{Z}$ and $Z^{*}$ always increase with $\gamma$.

${ }^{28}$ These numbers include all firms and not just the R\&D sector. Still, heterogeneity across countries in the size of the SME sector becomes obvious. 
due to patent protection. Structural and employment policies can change $\sigma$ and $\lambda$. Firm turnover is shaped by regulations that determine market entry possibilities and employment protection laws can influence the productivity of workers. Thus, the model can serve as a basis for a qualitative assessment of various policies.

To motivate such an assessment it is sufficient to look at EU policies in the past. The EU policies directed to SMEs are multidimensional. A recent review of them can be found in Dannreuther (2007). The EU tries to promote small businesses since the European Year of the SME 1982 (EYSME). In 1986 the SME Action Program was launched which addressed market failures and tried to improve the business environment. The second phase of SME policy began in the 1990s and was characterized by more sophisticated efforts towards SMEs. The final phase of SME policy started in 2000 with the Lisbon process. It aims at a stronger coordination of the member countries SME policies. Through the Lisbon process targets were defined which work as benchmarks for evaluating the policy measures. As Dannreuther (2007) points out, the SME policy of the EU became a very important element of the EU economic policy. This is also reflected in the Small Business Act of 2008 and the increased role of the European Investment Bank in financing small businesses (see EC 2010). Also the responses to the financial crises include specific policies designed for the SME sector. The increasing finance problems for SMEs have been recognized at the OECD Turin Round Table Meeting (see OECD 2009). In Germany the public KfW bank set up special credit programs in collaboration with private banks for SMEs where the KfW takes over a considerable fraction of the credit risks. On the European level, the European Investment Bank set up a credit program directed to SMEs with a volume of $30 \mathrm{~b} €$ over the period 2008 to 2010 .

We conclude that after almost 30 years after the introduction of the first programs at the European level, promoting SMEs is still an important topic. This seems to imply that after 30 years the goals have not been reached yet 
and there is still need for further policy interventions. It might also be possible that the goals are not reachable through some of the policies considered. Based on our results, there seems to be need for a careful evaluation of the programs. Their effects on growth and productivity might be different in different economies, depending on the importance of the SME sector in the different countries. Thus, identical policies might have a different impact in every country with also possibly different signs. The issue might get even more complex if sector heterogeneity of an economy is considered. Different sectors of an economy might be characterized by different firm size distributions. This in turn demands policies that are tailored to these different sectors. Policies that do not differentiate with respect to that might lead to very different outcomes across countries as well as across sectors.

\section{Conclusion}

Empirical evidence suggests that there might be a trade-off between SMEs and large enterprises defined by heterogeneity in R\&D productivity and credit constraints. Building on this argument, our theoretical model suggests an optimal firm heterogeneity with respect to growth and the long run level of ideas.

Analyzing the results of this model reveals that it might be a good idea to evaluate the existing policies regarding their appropriateness for the economy to foster growth. The size and the sign of effects might depend on settings that are different across countries and even sectors. Caution might be necessary because the same policies might lead to different results. This is especially important considering harmonized EU wide policies. 


\section{References}

Acs, Z. J. and D. B. Audretsch (1987): Innovation in Large and Small Firms. Economics Letters, 23, 109-112 .

Acs, Z. J. and D. B. Audretsch (1988): Innovation in Large and Small Firms: An Empirical Analysis. American Economic Review, 78, 678-690.

Acs, Z. J. and D. B. Audretsch (1990): Innovation and Small Firms. Cambridge, MIT Press.

Acs, Z. J. and D. B. Audretsch (1991): R\&D, Firm Size, and Innovative Activity. In: Z. J. Acs and D. B. Audretsch (eds.): Innovation and Technological Change: An International Comparison, New York, Harvester Wheatsheaf.

Aghion, P., T. Fally and S. Scarpetta (2007): Credit Constraints as a Barrier to the Entry and Post-Entry Growth of Firms. Economic Policy, 52, 731-779.

Aghion, P., S. Bond, A. Klemm and I. Marinescu (2004): Technology and Financial Structure: Are Innovative Firms Different? Journal of the European Economic Association, 2, 277-288.

Aghion, P. and P. Howitt (1992): A Model of Growth through Creative Destruction. Econometrica, 60, 323-351.

Aghion, P. and P. Howitt (1998): Endogenous Growth Theory. MIT Press.

Almeida, H. and M. Campello, (2004): Financial Constraints, Asset Tangibility, and Corporate Investment. Review of Financial Studies, 20, 1429-1460.

Altman, E. I. and G. Sabato (2005): Effects of the New Basel Capital Accord on Bank Capital Requirements for SMEs. Journal of Financial Services Research, 28, 15-42. 
Angelini, P. and A. Generale (2008): On the Evolution of Firm Size Distributions. American Economic Review, 98, 426-438.

Audretsch, D. B. (2007): From small business promotion to creating an entrepreneurial society. CESifo Forum, 8(2), 3-6.

Audretsch, D.B. and M. C. Keilbach (2004): Entrepreneurship and Regional Growth: An Evolutionary Interpretation. Journal of Evolutionary Economics, 14, 605-616.

Audretsch, D. B. and A. R. Thurik (2001): Linking Entrepreneurship to Growth. OECD Science, Technology and Industry Working Papers 2001/2.

Ayyagari, M., A. Demirgüc-Kunt and T. Beck (2007): Small and Medium Enterprises across the Globe. Small Business Economics, 29, 415-434..

Baldwin, R. E. and F. Robert-Nicoud (2008): Trade and growth with heterogeneous firms. Journal of International Economics, 74, 21-34.

Beck, T., A. Demirgüç-Kunt, L. Laeven and V. Maksimovic (2006): The Determinants of Financing Obstacles. Journal of International Money and Finance, 25, 932-952.

Berger, A. N. (2006): Potential Competitive Effects of Basel II on Banks in SME Credit Markets in the United States. Journal of Financial Services Research, 29, 5-36.

Bernanke, B. S., M. Gertler and S. Gilchrist (1996): The Financial Accelerator and the Flight to Quality. Review of Economics and Statistics, 78, $1-15$.

Bernanke, B. S., M. Gertler and S. Gilchrist (1999): The Financial Accelerator in a Quantitative Business Cycle Framework. In: J. B. Taylor and M. Woodford (ed.), Handbook of Macroeconomics, 1st ed., vol. 1, ch. 21, 1341-1393. 
Bertschek, I. and H. Entorf (1996): On Nonparametric Estimation of the Schumpeterian Link between Innovation and Firm Size. Empirical Economics 21, 401-426.

BIS (2009): Strengthening the resilience of the banking sector. Bank for International Settlements, Basel.

Bond, E., J. R. Tybout and H. Utar (2008): Credit Rationing, Risk Aversion and Industrial Evolution in Developing Countries. NBER Working Paper No. 14116.

Bound, J. C., C. Cummins, Z. Griliches, B. H. Hall and A. Jaffe (1984): Who Does R\&D and Who Patents. In Z. Griliches (ed.): R\&D, Patents and Productivity, Chicago, University Press.

Cabral, L. M. B. and J. Mata (2003): On the Evolution of the Firm Size Distribution: Facts and Theory. American Economic Review, 93, 10751090.

Carree, M. A. and A. R. Thurik (1998): Small Firms and Economic Growth in Europe. Atlantic Economic Journal, 26, 137-146.

Cohen, W. M., and S. Klepper (1996): A Reprise of Size and R\&D. Economic Journal, 106, 925-951.

Cremer, J. and M. Sirbu (1978): Une analyse econometrique de l'effort de recherché et developpement de l'industrie Francaise. Revue Economique, 29, 940-954.

Czarnitzki, D. and H. Hottenrott (2011): R\&D investment and financing constraints of small and medium-sized firms, Small Business Economics, $36,65-83$.

Dannreuther, C. (2007): EU SME policy: On the edge of governance. CESifo Forum, 8(2), 7-13. 
Devereux, M. and F. Schiantarelli (1990): Investment, Financial Factors and Cash Flow from U.K. Panel Data. In: G. Hubbard (ed.): Information, Capital Markets and Investment, University of Chicago Press.

EC (2010): Lisbon Strategy Evaluation Document. Commission Staff Working Document, Brussels.

ECB (2009): The Euro Area Bank Lending Survey - January 2009 -. European Central Bank, Frankfurt.

Entorf, H. (1988): Die endogene Innovation. Eine mikro-empirische Analyse von Produktphasen als Innovationsindikatoren. Jahrbücher für Nationalökonomie und Statistik, 204, 175-189.

Gale, D. and M. Hellwig (1985): Incentive-Compatible Debt Contracts: The One-Period Problem. Review of Economic Studies, 52, pages 647-663

Gertler, M. (1988): Financial Structure and Aggregate Economic Activity: An Overview. Journal of Money, Credit, and Banking, 20, 559-596.

Gorodnichenko, Y. and M. Schnitzer (2010): Financial Constraints and Innovation: Why Poor Countries Don't Catch Up. CEPR Working Paper No. 7721.

Greenwald B. C. and J. E. Stiglitz (1987): Imperfect Information, Credit Markets and Unemployment. European Economic Review, 31, 444-456.

Grunert, J., V. Kleff, L. Norden und M. Weber (2002): Mittelstand und Basel II: Der Einfluss der neuen Eigenkapitalvereinbarung für Banken auf die Kalkulation von Kreditzinsen. Zeitschrift für Betriebswirtschaft, ZfB, 10/2002, 1-20.

Hall, B. H., A. Jaffe and M. Trajtenberg (2005): Market Value and Patent Citations. RAND Journal of Economics, 36, 16-38. 
Helpman, E., M. J. Melitz and S. R. Yeaple (2004): Export versus FDI with Heterogeneous Firms. American Economic Review, 94, 300-316.

Helpman, E., O. Itskhoki and S. Redding (2008): Wages, Unemployment and Inequality with Heterogenous Firms and Workers. NBER Working Paper No. 14122.

Hurst, E. and A, Lusardi (2004): Liquidity Constraints, Household Wealth, and Entrepreneurship. Journal of Political Economy, 112, 319-347.

Idson, T. L. and W. Y. Oi (1999): Workers are More Productive in Large Firms, The American Economic Review, 89, 104-108.

Jacobson, T., J. Lindé and K. Roszbach (2005): Credit Risk Versus Capital Requirements under Basel II: Are SME Loans and Retail Credit Really Different? Journal of Financial Services, 28, 43-75.

Jones, C. I. (1995): R\&D-Based Models of Economic Growth. Journal of Political Economy, 103, 759-784.

Jones, C. I. (1999): Growth: With or Without Scale Effects? American Economic Review, Papers and Proceedings, 89, 139-144.

Jones, C. I. (2005): Growth and Ideas. In: Aghion, P. and S. Durlauf (2005): Handbook of Economic Growth. North-Holland

Jousten, A. (2007): SMEs and the tax system: What is so different about them? CESifo Forum, 8(2), 14-20.

Klees, S. and B. Veldhues (2008): Ausgewählte Ergebnisse für kleine und mittlere Unternehmen in Deutschland 2005. Statistisches Bundesamt Wirtschaft und Statistik 3/2008.

Klette, T. J. and S. Kortum (2004): Innovating Firms and Aggregate Innovation. Journal of Political Economy, 112, 986-1018. 
Lelarge, C., D. Sraer and D. Thesmar (2010): Entrepreneurship and Credit Constraints: Evidence from a French Loan Guarantee Program. In J. Lerner and A. Schoar (eds.): International Differences in Entrepreneurship. NBER Books, National Bureau of Economic Research Inc.

Lotti, F. and F. Schivardi (2005): Cross Country Differences in Patent Propensity: A Firm-Level Investigation. Giornale degli Economisti e Annali di Economia, 64, 469-502.

Luttmer, G. J. (2007): Selection, Growth, and the Size Distribution of Firms. Quarterly Journal of Economics, 122, 1103-1144.

Mata, J. (1996): Markets, Entrepreneurs and the Size of New Firms. Economics Letters, 52, 89-94.

Musso, P. and S. Schiavo (2008): The Impact of Financial Constraints on Firm Survival and Growth. Journal of Evolutionary Economics, 18, 135149.

OECD (2009): Turin Round Table Meeting on the Impact of the Global Crisis on SME \& Entrepreneurship Financing and Policy Responses. Chairs Summary. Available at http://www.oecd.org/dataoecd/36/27/42514077.pdf.

Pagano, P. and F. Schivardi (2003): Firm Size Distribution and Growth, Scandinavian Journal of Economics, 105, 255-274.

Papageorgiou, C. (2003): Imitation in a Non-Scale R\&D Growth Model. Economics Letters, 80, 287-294.

Pavitt, K., M. Robson and J. Townsend (1987): The Size Distribution of Innovation Firms in the UK: 1945-1983. Journal of Industrial Economics, $35,297-317$.

Peretto, P.F. (1998): Technological Change, Market Rivalry, and the Evolution of the Capitalist Engine of Growth, Journal of Economic Growth, vol. 3, pp. 53-80. 
Peretto, P.F. (1999a): Cost Reduction, Entry, and the Interdependence of Market Structure and Economic Growth?, Journal of Monetary Economics, vol. 43 n. 1, pp. 173-195.

Peretto, P.F. (1999b): Firm Size, Rivalry and the Extent of the Market in Endogenous Technological Change, European Economic Review, vol. 43 n.9, pp. $1747-1773$.

Plehn-Dujowich, J. (2007): Innovation, Firm Size, and RDSearch. Economics Bulletin, 12, 1-8.

Saurina, J. and C. Trucharte (2004):The Impact of Basel II on Lending to Small- and Medium-Sized Firms: A Regulatory Policy Assessment Based on Spanish Credit Register Data. Journal of Financial Services Research, $26,121-144$.

Scellato, G. (2007): Patents, firm size and financial constraints: an empirical analysis for a panel of Italian manufacturing firms. Cambrigde Journal of Economics, 31, 55-76.

Townsend, R. M. (1979): Optimal Contracts and Competitive Markets with Costly State Verification. Journal of Economic Theory, 21, 265-293.

Verspagen, B. (1999): Large Firms and Knowledge Flows in the Dutch R\&D System: A Case Study of Philips Electronics, Technology Analysis \& Strategic Management, 11, 211-233.

Wagenvoort, R. (2003a): Are Finance Constraints Hindering the Growth of SMEs in Europe? EIB Papers, 7, 22-50.

Wagenvoort, R. (2003b): SME Finance in Europe: Introduction and Overview. EIB Papers, 8, 10-20.

Yeaple, S. R. (2005): A Simple Model of Firm Heterogeneity, International Trade, and Wages. Journal of International Economics, 65, 1-20. 


\section{Appendix}

\section{A.1 Derivation of Equation (4)}

Let $\dot{Z}_{a}$ denote the flow of ideas produced by a firm with relative productivity $a \equiv A_{a} / A$ :

$$
\dot{Z}_{a}=\mu L_{a}^{\lambda}\left(\frac{A_{a}}{A}\right)^{\phi} Z^{\psi}
$$

The parameters $\mu, \lambda$, and $\psi$ satisfy

$$
\begin{aligned}
& 0<\mu, \lambda, \psi, \\
& 1>\lambda, \psi .
\end{aligned}
$$

The parameter $\phi$ determines the role played by the distance between the firm's initial productivity parameter $A_{a}$ and the current leading edge technology level $A$. A firm born at some $t=t_{0}$ is equipped with the current state of the art technology, $A_{a}=A\left(t_{0}\right)$, and keeps this level until it exits the market. Therefore, the sign of parameter $\phi$ determines whether the distance to the frontier hampers the firm's productivity $(\phi>0)$ or promotes it $(\phi<0)$. The latter case indicates an economy in which a growing distance to the frontier increases the potential for imitating, whereas in the former case innovation is the driving force of growth. The parameter $\psi$ reflects a technological spill over effect from the aggregate level of ideas $Z$ currently available.

Let $F(a)$ denote the distribution of $a \in[0,1]$, so that

$$
\dot{Z}=\int_{0}^{1} \dot{Z}_{a} d F(a)
$$

represents the relation between the production of ideas at the level of the individual firm $a$ and the aggregate flow of ideas.

Let $g \equiv \dot{Z} / Z$ denote the growth rate of ideas. We assume a given mass of firms of size one. At each instant of time a fraction of $\sigma_{1} g$ this firms exits and new firms enter so that the mass of firms stays constant. Let $G\left(A_{a}, t\right)$ denote the mass of firms $i$ with $A_{i} \leq A_{a}$. Consider a firm entering at $t=t_{0}$ so that 
the mass of firms behind this firm equals one, $G\left(A_{a}, t_{0}\right)=1$. As new firms enter with rate $\sigma_{1} g$, the mass of firms behind $A_{a}=A$ diminishes at the rate

$$
\frac{\dot{G}\left(A_{a}, t\right)}{G\left(A_{a}, t\right)}=-\sigma_{1} g
$$

The solution of this differential equation is

$$
G\left(A_{a}, t\right)=G\left(A_{a}, t_{0}\right) e^{-\sigma_{1} \int_{t_{0}}^{t} g(s) d s}=e^{-\sigma_{1} \int_{t_{0}}^{t} g(s) d s} .
$$

As in Aghion and Howitt (1998), p. 88, we assume that the growth rate of the leading edge technology $A$ is proportional to the growth rate of the economy $g$ :

$$
\dot{A}=\sigma_{2} g A
$$

The solution of this differential equation is

$$
A(t)=A\left(t_{0}\right) e^{\sigma_{2} \int_{t_{0}}^{t} g(s) d s}
$$

so that with $A_{a}=A\left(t_{0}\right)$ :

$$
\frac{A_{a}}{A}=e^{-\sigma_{2} \int_{t_{0}}^{t} g(s) d s}=\left(G\left(A_{a}, t\right)\right)^{\sigma_{2} / \sigma_{1}},
$$

and, hence,

$$
F(a) \equiv G\left(A_{a}=a A, t\right)=\left(\frac{A_{a}}{A}\right)^{\sigma}=a^{\sigma}, \quad \sigma \equiv \sigma_{1} / \sigma_{2}
$$

as the mass of firms with relative productivity smaller than some given $a$.

\section{A.2 Derivation of Equation (7)}

Using $v_{a}=\nu a^{\gamma}$, equation (5) can be written as:

$$
w=\mu \lambda V \nu a^{\gamma+\phi} Z^{\psi} L_{a}^{\lambda-1} .
$$

Solving for $L_{a}$ gives:

$$
L_{a}=\left(\frac{w}{\mu \nu \lambda V Z^{\psi}}\right)^{\frac{1}{\lambda-1}} a^{\frac{\gamma+\phi}{1-\lambda}}
$$


Substituting for $L_{a}^{\lambda}$ in (A.1) yields

$$
\dot{Z}_{a}=\Delta a^{\delta}, \Delta=\left(\frac{w}{\mu \nu \lambda V Z^{\psi}}\right)^{\frac{\lambda}{\lambda-1}}, \delta=\frac{\phi+\lambda \gamma}{1-\lambda} .
$$

Using this result and the density $f(a)=\sigma a^{\sigma-1}$ in equation (6) gives:

$$
\frac{M}{K}=1-\frac{\Delta \int_{0}^{1} \nu a^{\gamma} \sigma a^{\sigma-1} a^{\delta} d a}{\Delta \int_{0}^{1} \sigma a^{\sigma-1} a^{\delta} d a}=1-\nu \frac{\sigma(1-\lambda)+\phi+\lambda \gamma}{\sigma(1-\lambda)+\phi+\gamma}
$$

which equals (7) in the main body of the paper.

\section{A.3 Derivation of Equation (8)}

Integration of equation (A.3) yields

$$
\begin{aligned}
L \equiv & \int_{0}^{1} L_{a} f(a) d a=\int_{0}^{1} L_{a} \sigma a^{\sigma-1} d a, \\
& =\left(\frac{w}{\mu \nu \lambda V Z^{\psi}}\right)^{\frac{1}{\lambda-1}} \sigma \int_{0}^{1} a^{\sigma-1+\frac{\phi+\gamma}{1-\lambda}} d a, \\
& =\left(\frac{w}{\mu \nu \lambda V Z^{\psi}}\right)^{\frac{1}{\lambda-1}} \frac{\sigma(1-\lambda)}{\sigma(1-\lambda)+\phi+\gamma} .
\end{aligned}
$$

For given aggregate labor supply $L$, this equation determines the market clearing wage $w$. Together with (A.3) this equation implies:

$$
L_{a}=a^{\frac{\phi+\gamma}{1-\lambda}} \underbrace{\left[\frac{\sigma(1-\lambda)+\phi+\gamma}{\sigma(1-\lambda)}\right]}_{\left[\int_{0}^{1} a^{\frac{\phi+\gamma}{1-\lambda}} d F(a)\right]^{-1}} L .
$$

Using this to eliminate $L_{a}$ in (A.1) yields:

$$
\dot{Z}_{a}=\mu\left[\frac{\sigma(1-\lambda)+\phi+\gamma}{\sigma(1-\lambda)}\right]^{\lambda} L^{\lambda} a^{\frac{\lambda[\phi+\gamma]}{1-\lambda}} a^{\phi} Z^{\psi}
$$

so that

$$
\begin{gathered}
\dot{Z}=\int_{0}^{1} \dot{Z}_{a} f(a) d a=\mu\left[\frac{\sigma(1-\lambda)+\phi+\gamma}{\sigma(1-\lambda)}\right]^{\lambda} L^{\lambda} Z^{\psi} \\
\times \int_{0}^{1} a^{\frac{\lambda[\phi+\gamma}{1-\lambda}} a^{\phi} \sigma a^{\sigma-1} d a \\
\dot{Z}=\mu\left[\frac{\sigma(1-\lambda)}{\sigma(1-\lambda)+\phi+\gamma}\right]^{-\lambda} L^{\lambda} Z^{\psi} \frac{\sigma(1-\lambda)}{\sigma(1-\lambda)+\phi+\lambda \gamma} .
\end{gathered}
$$

Dividing both sides by $Z$ provides equation (8) in the main body of the paper. 


\section{A.4 Derivation of Equation (9)}

Let

$$
\begin{aligned}
\Psi(\sigma) \equiv=\frac{\dot{Z}}{Z}= & \mu L^{\lambda} Z^{\psi-1}\left(\frac{\sigma(1-\lambda)}{\sigma(1-\lambda)+\phi+\gamma}\right)^{-\lambda} \\
& \times\left(\frac{\sigma(1-\lambda)}{\sigma(1-\lambda)+\phi+\gamma \lambda}\right)
\end{aligned}
$$

Differentiating with respect to $\sigma$ yields:

$$
\begin{aligned}
\Psi^{\prime}(\sigma)= & -\lambda \Psi \frac{\sigma(1-\lambda)+\phi+\gamma}{\sigma(1-\lambda)} \\
& \times \frac{(\sigma(1-\lambda)+\phi+\gamma)(1-\lambda)-\sigma(1-\lambda)^{2}}{(\sigma(1-\lambda)+\phi+\gamma)^{2}} \\
& +\psi \frac{\sigma(1-\lambda)+\phi+\lambda \gamma}{\sigma(1-\lambda)} \\
& \times \frac{(\sigma(1-\lambda)+\phi+\lambda \gamma)(1-\lambda)-\sigma(1-\lambda)^{2}}{(\sigma(1-\lambda)+\phi+\lambda \gamma)^{2}},
\end{aligned}
$$

which can be simplified to

$$
\Psi^{\prime}(\sigma)=\frac{\Psi}{\sigma} \underbrace{\left[\frac{\phi+\lambda \gamma}{\sigma(1-\lambda)+\phi+\lambda \gamma}-\frac{\lambda(\phi+\gamma)}{\sigma(1-\lambda)+\phi+\lambda \gamma}\right]}_{\Delta} .
$$

Setting the expression in brackets equal to zero gives (9). At $\sigma^{*}$ the expression $\sigma(1-\lambda)+\phi+\gamma$ is given by

$$
\sigma^{*}(1-\lambda)+\phi+\gamma=-(\phi+\gamma) \frac{\lambda \gamma}{\phi} .
$$

In order to determine whether the zero of $\Psi$ is indeed a maximum, we must consider the second derivative. Differentiating (A.5) gives:

$$
\begin{aligned}
& \Psi^{\prime \prime}(\sigma)=\frac{\Psi^{\prime}(\sigma)}{\sigma} \Delta-\frac{\Psi(\sigma)}{\sigma^{2} \Delta} \\
&+\frac{\Psi(\sigma)}{\sigma}\left[-\frac{(1-\lambda)[\phi+\lambda \gamma]}{[\sigma(1-\lambda)+\phi+\lambda \gamma]^{2}}\right. \\
&\left.+\frac{\lambda(1-\lambda)[\phi+\gamma]}{[\sigma(1-\lambda)+\phi+\gamma]^{2}}\right]
\end{aligned}
$$


Since $\Delta=0$ at $\sigma=\sigma^{*}$, and

$$
\frac{\phi+\lambda \gamma}{\sigma(1-\lambda)+\phi+\lambda \gamma}=\frac{\lambda[\phi+\gamma]}{\sigma(1-\lambda)+\phi+\gamma}
$$

we get

$$
\Psi^{\prime \prime}\left(\sigma^{*}\right)=-\frac{\gamma \Psi}{\sigma} \frac{(1-\lambda)^{2}}{[\sigma(1-\lambda)+\phi+\lambda \gamma]^{2}} \times \frac{\phi+\lambda \gamma}{\sigma(1-\lambda)+\phi+\gamma} .
$$

With respect to the sign of $\Psi^{\prime \prime}\left(\sigma^{*}\right)$, we must distinguish three cases: ${ }^{29}$

1. $\phi<0$, which corresponds to column one in Table 1:

Thus, $\phi+\gamma<0, \phi+\lambda \gamma<0$, and equation (9) yields $\sigma^{*}>0$. Since $\Psi^{\prime \prime}\left(\sigma^{*}\right)<0$ from (A.7), $\sigma^{*}$ indeed maximizes the growth rate.

2. $\phi>0$, which corresponds to column two in Table 1:

In this case we have to differentiate between two subcases:

2.1. $\phi+\gamma<0$ and $\phi+\lambda \gamma>0$ :

Equation (9) implies $\sigma^{*}>0$ while (A.7) yields $\Psi^{\prime \prime}\left(\sigma^{*}\right)>0$ so that $\sigma^{*}$ minimizes the growth rate. However, for our model to be meaningful $\sigma(1-\lambda)+\phi+\gamma$ needs to be positive. Yet, as can be seen from (A.6), at $\sigma^{*}$ this expression is always negative. For $\sigma>\sigma^{*}$ and in the range where $\sigma(1-\lambda)+\phi+\gamma>0$ the growth rate is increasing with $\sigma$.

2.2. $\phi+\gamma<0$ and $\phi+\lambda \gamma<0$ :

Equation (9) implies $\sigma^{*}<0$. This case obviously contradicts our assumption $\sigma>0$. However, for all positive $\sigma$ in the rage where $\sigma(1-\lambda)+\phi+\gamma>0$ holds, $\Psi^{\prime}(\sigma)>0$.

\section{A.5 The Balanced Growth Path}

Consider the growth equation (8):

$$
\begin{aligned}
g \equiv \frac{\dot{Z}}{Z}= & \mu L^{\lambda} Z^{\psi-1}\left(\frac{\sigma(1-\lambda)}{\sigma(1-\lambda)+\phi+\gamma}\right)^{-\lambda} \\
& \times\left(\frac{\sigma(1-\lambda)}{\sigma(1-\lambda)+\phi+\gamma \lambda}\right) .
\end{aligned}
$$

\footnotetext{
${ }^{29}$ Remember that we assume $\gamma<0$.
} 
Differentiating this equation with respect to time yields:

$$
\frac{\dot{g}}{g}=\lambda \frac{\dot{L}}{L}+(\psi-1) g
$$

Setting this equation equal to zero and solving for $n=\dot{L} / L$ yields

$$
g^{*} \equiv \frac{\dot{Z}^{*}}{Z^{*}}=\frac{\lambda}{1-\psi} n
$$

which is equation (12) in the main body of the paper. Substitution for $\dot{Z} / Z$ in equation (8) and solving for $Z^{*}$ yields equation (12).

\section{A.6 Comparative Statics of the Distribution Parameter}

$$
\begin{aligned}
\frac{\partial \sigma^{*}}{\partial \gamma} & =-\frac{2 \lambda \gamma+(1+\lambda) \phi}{\phi(1-\lambda)}<0 \\
\frac{\partial \sigma^{*}}{\partial \phi} & =-(1-\lambda) \frac{\phi(\lambda \gamma+\phi+\gamma+\phi)-(\gamma+\phi)(\lambda \gamma+\phi)}{\phi^{2}(1-\lambda)^{2}} \\
& =\sigma^{*}\left(\frac{1}{\gamma+\phi}+\frac{1}{\lambda \gamma+\phi}+\frac{1}{\phi}\right)<0 \\
\frac{\partial \sigma^{*}}{\partial \lambda} & =-\frac{\phi(1-\lambda) \gamma(\gamma+\phi)+(\gamma+\phi)(\lambda \gamma+\phi) \phi}{\phi_{1}^{2}(1-\lambda)^{2}} \\
& =\sigma^{*}\left(\frac{\gamma}{\lambda \gamma+\phi}+\frac{1}{1-\lambda}\right)>0 .
\end{aligned}
$$

\section{A.7 Comparative Statics of the Growth Rate and level of Ideas}

$$
\begin{aligned}
\frac{\partial \frac{\dot{Z}}{\partial \gamma}}{\partial \gamma} & =\lambda \frac{\dot{Z}}{Z}\left(\frac{1}{\sigma(1-\lambda)+\phi+\gamma}-\frac{1}{\sigma(1-\lambda)+\phi+\lambda \gamma}\right) \\
\frac{\partial \frac{\dot{Z}}{\partial \phi}}{\partial} & =\lambda \frac{\dot{Z}}{Z} \frac{1}{\sigma(1-\lambda)+\phi+\gamma}-\frac{\dot{Z}}{Z} \frac{1}{\sigma(1-\lambda)+\phi+\lambda \gamma} \\
& =-\frac{(1-\lambda)[\sigma(1-\lambda)+\phi+(1+\lambda) \gamma]}{[\sigma(1-\lambda)+\phi+\gamma][\sigma(1-\lambda)+\phi+\lambda \gamma]}, \\
\frac{\partial Z^{*}}{\partial \gamma} & =\frac{1}{1-\psi} \frac{\partial \frac{\dot{Z}}{\partial}}{\partial \gamma} \\
\frac{\partial Z^{*}}{\partial \phi} & =\frac{1}{1-\psi} \frac{\partial \frac{\dot{Z}}{\partial}}{\partial \phi} .
\end{aligned}
$$

